OPEN ACCESS

Edited by:

Ertugrul Kilic,

Istanbul Medipol University, Turkey

Reviewed by:

Hulya Karatas,

Hacettepe University, Turkey

Anupom Borah,

Assam University, India

*Correspondence:

Mengqi Zhang

zhangmengqi0102@126.com

Specialty section:

This article was submitted to

Cellular Neuropathology,

a section of the journal

Frontiers in Cellular Neuroscience

Received: 09 September 2021 Accepted: 15 November 2021

Published: 14 December 2021

Citation:

Yu Q, Liu W, Chen Z and Zhang M (2021) Specificity Protein 1: A Protein

With a Two-Sided Role in Ischemic

Stroke.

Front. Cell. Neurosci. 15:757670.

doi: 10.3389/fncel.2021.757670

\section{Specificity Protein 1: A Protein With a Two-Sided Role in Ischemic Stroke}

\author{
Qinyang Yu ${ }^{1,2}$, Wangyang Liu ${ }^{1,2}$, Zhuohui Chen ${ }^{1,2}$ and Mengqi Zhang ${ }^{1,2 *}$ \\ ${ }^{1}$ Department of Neurology, Xiangya Hospital, Central South University, Changsha, China, ${ }^{2}$ National Clinical Research Center \\ for Geriatric Disorders, Xiangya Hospital, Central South University, Changsha, China
}

Stroke is one of the leading causes of death and disability worldwide. However, there is a lack of effective medications to speed up the recovery process. Ischemic stroke, as the result of cerebral infarction or cerebral artery narrowing, is accompanied by hemiplegia or impaired consciousness. There are many transcription factors involved in the development of this condition, whose alterations can influence or signal the prognostic outcomes of ischemic stroke. Among them, the augmented expression of specificity protein 1 (SP1) can participate in the progression of the disease by binding DNA to regulate the transcriptions of many genes. Different studies have provided different answers as to whether SP1 plays a positive or a negative role in ischemic stroke. On the one hand, SP1 can play a cytoprotective role as both an antioxidant and anti-apoptotic agent for neurons and glial cells. On the other hand, it can also damage neuronal cells by promoting inflammation and exacerbating brain edema. In this review, we highlight the roles of SP1 in ischemic stroke and shed light on the underlying mechanism.

Keywords: ischemic stroke, oxidative stress, cerebral edema, neuroprotection, specificity protein 1 (SP1)

\section{INTRODUCTION}

Stroke, classified as both ischemic stroke and hemorrhagic stroke, is responsible for major deaths and disabilities worldwide. Ischemic strokes account for $71 \%$ of strokes worldwide, and the current reperfusion strategies include intravenous thrombolysis and endovascular thrombectomy. Most ischemic strokes originate from thromboembolism, and a small proportion is caused by small vessel diseases (Campbell et al., 2019). When cerebral blood vessels become narrow and cerebral blood flow $(\mathrm{CBF})$ declines for various reasons, the available glucose and oxygen will witness a decrease, resulting in a relative deficiency in energy production, disruption of the normal ion concentration gradient, and interference in normal membrane potential. Then, it is followed by the depolarization of the presynaptic membrane and an increase in excitatory amino acid transmitters (GonzálezNieto et al., 2020). In addition, the dysfunction of the $\mathrm{Na}^{+}-\mathrm{K}^{+}$ATPase will elevate the intracellular $\mathrm{Na}^{+}$concentration, thus further activating and reversing the $\mathrm{Na}^{+} / \mathrm{Ca}^{2+}$ exchanger. Under the action of excitatory amino acids, neurons release excitatory transmitters such as glutamate and dopamine. In the meanwhile, the intracellular $\mathrm{Ca}^{2+}$ will witness a rapid increase in glial cells and neurons, activating a variety of calmodulin-dependent and $\mathrm{Ca}^{2+}$-dependent enzymes that can disrupt cell structure and contribute to cell death (Abdullahi et al., 2018). Furthermore, the hyperexcitability of glutamate receptors drives neuronal production of NO synthases which is involved in the production of reactive oxygen species (ROS) (González-Nieto et al., 2020). When hypoxia occurs and the respiratory chain is in dysfunction, excess ROS and/or free radicals are generated in the cell, triggering a state of oxidative stress, which can damage the nucleic acids, 
proteins, and the structure of the cell membrane (Ayala et al., 2014). Furthermore, the dysfunction of the blood-brain barrier (BBB) and the release of signaling molecules from glial cells can promote inflammatory responses. Subsequently, excessive production of ROS and/or free radicals in neurons can cause structural damage and dysfunction of neuronal cells, predisposing the cells to apoptosis or necrosis (Campbell et al., 2019) (Figure 1). As a member of the SP family together with SP2, SP3, and SP4, SP1 serves as a crucial transcription factor and a multipotent oxidative stress response protein (Yeh et al., 2011). Participating in numerous downstream pathways, SP1 is known to be associated with 410 diseases including myocardial infarction, lipid metabolism disorders, and multiple cancers. It was found that 38 transcription factors were differentially expressed after transient middle cerebral artery occlusion (tMCAO) in mice, with SP1, SPi1, and Stat3 being the most significant (Rakers et al., 2019), and it has been hypothesized that SP1 and Argonaute 1 (AGO1) are the two major genes involved in ischemic stroke (Wei et al., 2020). Through facilitating the transcription of various antioxidant proteins, such as zinc finger protein 179 (Znf179), and various antioxidant enzymes, SP1 can affect the ion transporters on the cytoplasmic side to protect neurons, glial cells, and endothelial cells. However, there are still some mechanisms existing that play counterproductive roles and exacerbate the damage of cerebral ischemia. In this review, we have provided clear insight into the role of SP1 in ischemic stroke and further explored the therapeutic strategies associated with $\mathrm{SP} 1$ in ischemic stroke.

\section{GENE STRUCTURE, COMPOSITION, AND REGULATION OF SP1}

According to the GeneCards database, the SP1 gene is located on the long arm of chromosome 12 at position 12q13.13. Human SP1 is composed of 785 amino acids with a total molecular weight of 80,693 . Located in both the cytoplasm and nucleus of a cell, SP1 bears a high nuclear content and a low tissue specificity. It can be found in many organs such as the brain, kidney, pancreas, lymph, and bone marrow. Three zinc finger Cys2His2 structures, responsible for binding to GC-rich DNA sequences and enhancing gene transcription, make up the active centers of SP1.

The basic functions of SP1 include binding to basic helixloop-helix (bHLH) transcription factors (Zheng et al., 2018), acting as a DNA transcription activator (Gilmour et al., 2019), combining with histone acetyltransferases/histone deacetylases (Li et al., 2019a), and interacting with HMG frame structural domains (Kovacevic Grujicic et al., 2005) (Table 1).

The regulation of SP1 is mainly affected by posttranslational modifications such as phosphorylation, acetylation,

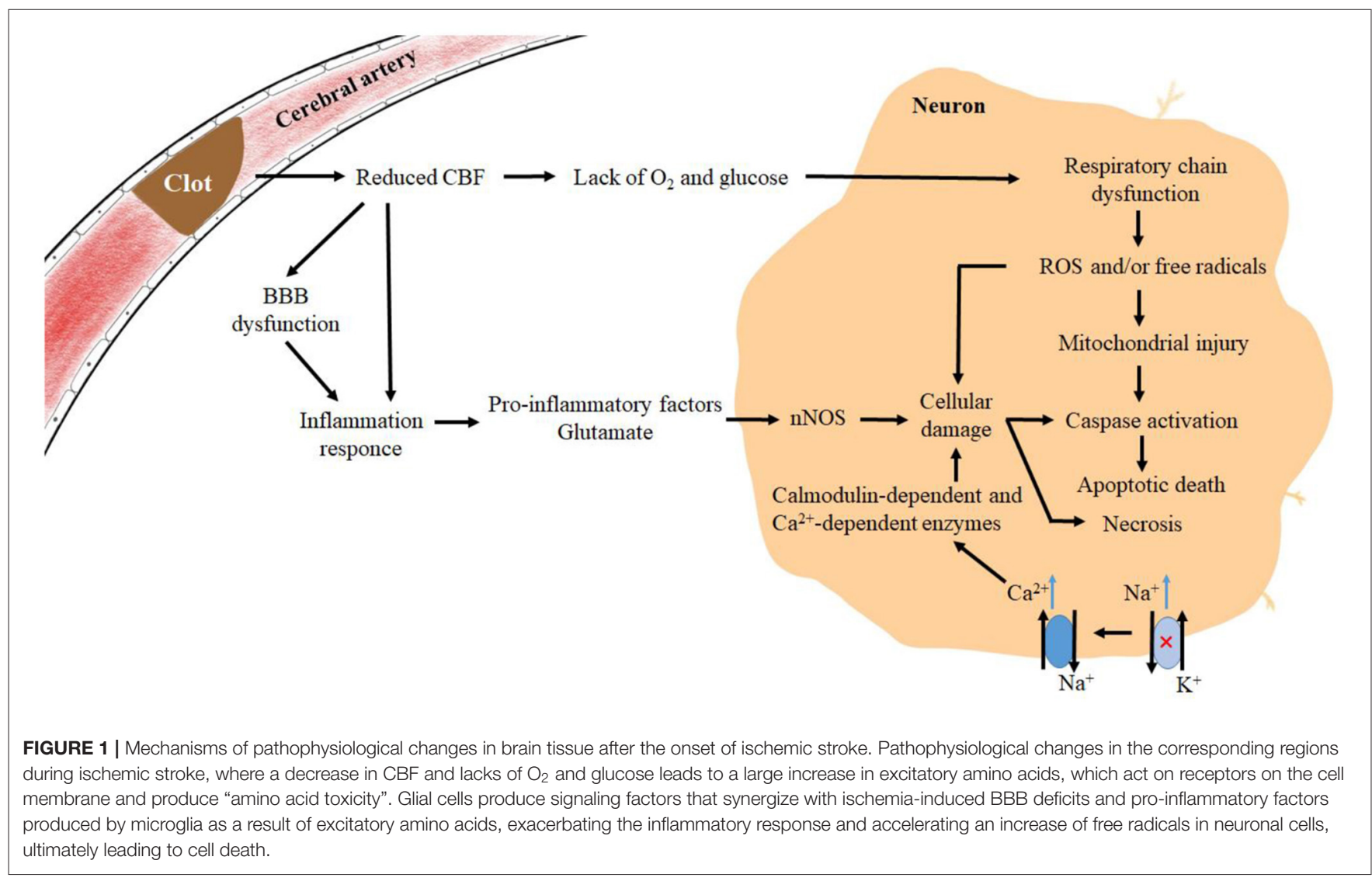


TABLE 1 | Basic functions and physiological significance of SP1.

\begin{tabular}{|c|c|c|}
\hline Function & Physiological significance & Reference \\
\hline Binding to transcription factor, basic helix-loop-helix (bHLH) & $\begin{array}{l}\text { Interacting non-covalently with the bHLH } \\
\text { superfamily and serving as an important regulatory } \\
\text { component of many developmental pathways }\end{array}$ & Zheng et al., 2018 \\
\hline DNA transcription activator & $\begin{array}{l}\text { Binding to specific sequences of DNA activating or } \\
\text { increasing specific gene sequences transcribed by } \\
\text { RNA polymerase II }\end{array}$ & $\begin{array}{l}\text { Gilmour et al., } \\
2019\end{array}$ \\
\hline Binding to histone acetyltransferase/histone deacetylase & $\begin{array}{l}\text { Increasing histone acetylation/deacetylation and } \\
\text { activating/repressing transcriptional activities of } \\
\text { genes }\end{array}$ & Li et al., 2019a \\
\hline Interacting with the high-mobility group (HMG) domain or HMG box & $\begin{array}{l}\text { Participating in the regulation of DNA-dependent } \\
\text { processes (transcription, replication, strand repair) }\end{array}$ & $\begin{array}{l}\text { Kovacevic Grujicic } \\
\text { et al., } 2005\end{array}$ \\
\hline
\end{tabular}

ubiquitylation, sumoylation, glycosylation, and proteolytic lysis. There are also cap-independent pathways, namely, the internal ribosome entry sites (IRES) pathway, which eventually raise the translation efficiency by adding highly selective SP1 ribosomes (Yeh et al., 2011).

\section{Posttranslational Modifications of SP1 Phosphorylation Modification of SP1}

Phosphorylation of SP1 can affect its transcriptional activity and stability. Currently, it is known that there are 61 phosphorylation sites of SP1, including 48 residues of serine, 10 residues of threonine, and 3 residues of tryptophan. Phosphorylation of SP1 will produce positive or negative regulation on DNA binding and transcriptional activity (Tan and Khachigian, 2009).

Phosphorylation of Sp1 at Ser101 depends on ATM, the major kinase responsible for Ser101 direct Sp1 phosphorylation. As DNA strand breaks accumulate, ATM phosphorylates transcription factor $\mathrm{Sp} 1$ and destabilizes it, which results in the downregulated transcription of the DNA base excision repair (BER) gene XRCC1, accompanied by decreased levels of DNA ligase III. Lower levels of both simultaneously increase the accumulation of DNA strand breaks, forming a vicious cycle, which is seen as a protective mechanism for removing unrepaired cells from permanent DNA strand breaks (Fletcher et al., 2018). The DNA binding ability and the transcription level of Sp1 change after the phosphorylation of Sp1 by different proteins (Tan and Khachigian, 2009).

\section{Other Modifications of SP1}

O-Linked $\mathrm{N}$-acetylglucosamine (O-GlcNAc) modification of SP1, induced by hyperglycemia, mediates the expression of intracellular adhesion molecule 1, thus further promoting inflammation (Zhang et al., 2017). This modification may inhibit the transcriptional activation of glycolytic genes (Lim et al., 2015). In addition, the acetylation of SP1 can boost the growth of glioblastoma (Yang et al., 2020).

\section{Regulation of Translation Efficiency: The Cap-Independent Pathways}

SP1 mRNA 5'-UTR contains a conserved sequence, the IRES, which is the translational regulatory element of
mRNA first identified in viruses (Godet et al., 2019; Arhab et al., 2020). It forms a complex of high affinity with the ribosome subunit and dynamically manipulates its conformation to promote protein synthesis. The ability of these IRES to form high-affinity ribosomal complexes enables the production of structural and biochemical models for certain initiation steps and plays an important role in the structural dynamics of eukaryotic ribosomes (Arhab et al., 2020). Cap-containing IRES mRNA can be translated through either cap-dependent or IRES-dependent mechanisms. Studies have indicated that, under hypoxic conditions, there is a shift from cap-dependent pathways to cap-independent and IRES-dependent pathways (Bornes et al., 2007).

In a male rat model of oxygen and glucose deprivation (OGD) by using endothelin, large amounts of reactive oxygen species and $\mathrm{H}_{2} \mathrm{O}_{2}$ can elevate SP1. Typical IRES regions have been identified upstream of the SP1 coding region, which are activated by $\mathrm{H}_{2} \mathrm{O}_{2}$ to collect more ribosomes binding to mRNA, thus boosting the translation efficiency of $\mathrm{SP} 1$. In short, $\mathrm{H}_{2} \mathrm{O}_{2}$ improves the translation efficiency of SP1 by selectively increasing the number of ribosomes associated with SP1 mRNA (Yeh et al., 2011).

\section{THE ROLE OF SP1 IN ISCHEMIC STROKE}

Ischemic stroke occurs when local blood flow to the brain is interrupted, followed by the hypoxia in nerve cells, glial cells, and endothelial cells in the ischemic region, where SP1 is upregulated and on the act. The role of SP1 in ischemic stroke can be divided into two different kinds, protective and damaging. The protective roles include its antioxidant, anti-apoptotic, anti-thrombotic effects, and its function in reducing brain edema through the formation of certain ion channels, while its damaging roles can be identified as a promoter of inflammation, a constricting factor of cerebral vessels, and an aggravator of brain edema through the formation of certain ion channels that serve as a doubleedged sword.

\section{Antioxidant Effect of SP1}

When nerve cells, glial cells, and endothelial cells are in an ischemic state and the respiratory chain is dysfunctional, excess 
reactive oxygen species and/or free radicals are generated intracellularly, putting the cells under oxidative stress. Biofilm structure is disrupted and lipid peroxidation occurs, producing toxic aldehyde products such as malondialdehyde (MDA) and 4-hydroxynonenal (4-HNE). Susceptible to these aldehyde modifications, the proteins and DNA are predisposed to functional and structural disorders. Moreover, MDA and hypoxia-inducible factor- $1 \alpha$ (HIF-1 $\alpha$ ) can upregulate SP1 gene expression. Antioxidant enzymes such as glutathione peroxidase (GPX), peroxidase (Prx), and superoxide dismutase (SOD) can inhibit oxidative damage. With the help of the reducing agent glutathione (GSH), GPX catalyzes the reduction of $\mathrm{H}_{2} \mathrm{O}_{2}$ or organic hydroperoxides into water or the corresponding alcohols (Ayala et al., 2014). SP1 attenuates the cellular oxidative stress state by directly or indirectly raising up the level of antioxidant enzymes.

Zinc finger protein 179, also known as RING finger protein 112 (Rnf112), is one of the most essential factors in the differentiation and development of the nervous system during embryogenesis, mainly expressed in the central nervous system. It serves as an important neuroprotector in ischemic stroke, neurodegenerative disease, and traumatic brain injury (Su et al., 2016; Chuang et al., 2017; Lee et al., 2018). In a neuronlike cell model (differentiated mouse neuroblastoma N2a cells), Znf179 was found to protect neurons against ROS by increasing the levels of peroxidase $3(\operatorname{Prx} 3)$ and superoxide dismutase 2 (SOD2). In addition, Znf179 attenuates apoptosis and TNF$\alpha$ production under $\mathrm{H}_{2} \mathrm{O}_{2}$ exposure ( $\mathrm{Su}$ et al., 2016). Apart from that, peroxide damage boosts the promoter activity of $\mathrm{Znf179}$. In the $\mathrm{Znf179}$ promoter region, there are at least seven conserved SP1-binding elements that promote Znf179 transcription through their bindings to SP1. Furthermore, experiments conducted with green fluorescent protein (GFP)Znf179-expressing cells have confirmed that the increase of Znf179 could induce the expression of its own promoter, forming a positive feedback loop (Chuang et al., 2017). Nerve growth factor (NGF) enhances the neuroprotective function of the SP1Znf179 pathway by elevating the level of SP1 phosphorylation via the phosphatidylinositol 3-kinase/PKC- $\zeta$ pathway (Chuang et al., 2017). To conclude, mediated by SP1 and promoted by NGF, the activation of Znf179 autoregulatory loop matters a lot in reducing $\mathrm{H}_{2} \mathrm{O}_{2}$-induced oxidative stress toxicity in cells (Chuang et al., 2017). SAHA, a histone deacetylase (HDAC) inhibitor, was shown to promote the dissociation of Znf179HDAC1 and the acetylation of the Znf179 gene in differentiated N2a cells, which could enhance neuroprotection. Furthermore, SAHA could recruit SP1 to the Znf179 promoter to form the Znf179-SP1 complex and activate the transcription of $\mathrm{Znf179}$ (Wu et al., 2018).

Peroxiredoxin $6(\operatorname{Prdx} 6)$ is a bifunctional protein with glutathione peroxidase and $\mathrm{Ca}^{2+}$-independent phospholipase $\mathrm{A} 2$ (aiPLA2) activities (Fisher, 2011). A study identifies another antioxidant mechanism in neurons, namely, the SP1/Prdx6 pathway. The binding of SP1 to each of the three SP1-binding sites in the Prdx6 promoter can upregulate Prdx6 expression (Jia et al., 2017). However, there is a lack of reports on the role of
aiPLA2 activity of Prdx6 in ischemic stroke. Additionally, SP1 binds to glutathione peroxidase 4 (GPX4) and the phospholipid hydrogen glutathione peroxidase ( $\mathrm{phGPx}$ ) promoter to regulate their expression and acts as an antioxidant (Dai et al., 2020).

TP53-induced glycolysis and apoptosis regulator (TIGAR) is a novel TP53-inducible protein involved in regulating both metabolic and neuroprotective pathways. Because of its structural similarity to phosphofructokinase-1 (FPK-1) and fructose-2,6bisphosphate kinase in the glycolytic pathway, it could inhibit glycolysis and divert metabolites to the pentose phosphate pathway (PPP) by elevating glucose-6-phosphate dehydrogenase (G-6-PD) level (Lee et al., 2015; Chen et al., 2018). Experiments have shown that SP1 binds to the TIGAR promoter to promote transcription (Zou et al., 2012). Under ischemia and OGD/reoxygenation, SP1 has a significant role in inducing TIGAR proteins in neurons and astrocytes, which has been confirmed in in vivo experiments in mice (Sun et al., 2015; Chen et al., 2018). Moreover, in astrocytes and neurons, SP1-induced TIGAR can counteract ROS and thus protect neurons and astrocytes by inhibiting NF- $\mathrm{B}$, reducing inflammatory factor levels, and increasing NADPH and GSH brought about by the PPP pathway, thereby reducing brain edema and shrinking the size of brain infarcts (Zhou et al., 2016; Chen et al., 2018; Duan et al., 2018).

\section{Anti-apoptosis Effect of SP1}

Each member of the inhibitors of apoptosis proteins (IAPs) contains at least one baculovirus inhibitor of apoptosis repeat (BIR) that prevents programmed cell death. Survivin is the smallest molecular member of the IAPs involved in cell cycle progression and apoptosis inhibition, and normally, it is expressed only in proliferatively active cells and is overexpressed in most human cancers (Wheatley and Altieri, 2019). During the onset of ischemic stroke, the level of survivin in vascular endothelial cells undergoes an upregulation. Upstream factors, such as Smac released from mitochondria, inhibit IAPs by binding to the BIR structural domain, and there is evidence that survivin compromises apoptosis by suppressing caspase activator Smac. In addition, survivin also directly binds to and inhibits caspase-3 (Mansour et al., 2012). Through the above pathways, survivin alleviates the risk of cerebral hemorrhage after ischemic stroke by mitigating the destruction of the BBB triggered by apoptosis (Mallolas et al., 2014). The promoter of the survivin gene has a typical CpG island and many SP1-binding sites, making it possible for SP1 to activate and upregulate survivin transcription, which can be found in various studies such as ovarian cancer (Mak et al., 2017; Wang et al., 2017).

\section{Preventing DNA Damage by Inducing Cox-2 Expression}

Under the ischemia-induced oxidative stress state, the phosphorylation of SP1 witnesses an upregulation. Then, SP1 promotes Cox-2 expression by binding to two SP1-binding sites proximal to the Cox-2 promoter. Either SP1 activity inhibition or Cox-2 deficiency exacerbates DNA damage in neurons (Lee et al., 2006). However, Cox-2 has also shown a pro-apoptotic effect in other diseases and nonneural cell 


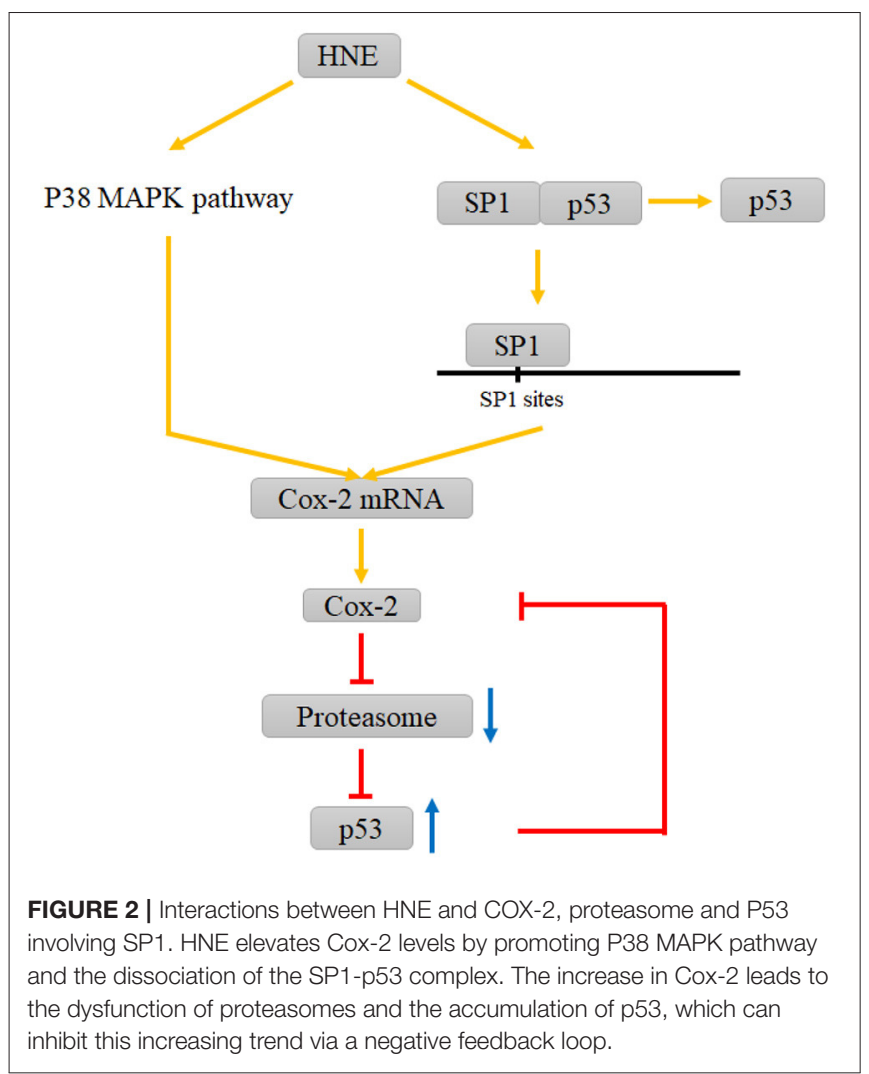

studies (An et al., 2014; Song et al., 2019). As mentioned earlier, 4-HNE is an electrophilic lipid peroxidation product that can dysfunction the target molecules such as proteins and nucleotides possible to further induce apoptosis (Sonowal and Ramana, 2019). It can not only stabilize Cox-2 mRNA via the p38 mitogen-activated protein kinase signaling pathway but also facilitate the dissociation of the SP1-p53 heterodimer to produce SP1 accompanied by SP1 nuclear translocation after binding to the Cox-2 promoter. Relevant studies have demonstrated that Cox-2 is adversely regulated by $\mathrm{p} 53$, and the possible mechanism underlying this process may be attributed to the downregulation role of the formation of the SP1-p53 complex on functional SP1. Also, the upregulated level of Cox-2 is followed by the dysfunction of proteasomes and the accumulation of p53 and ubiquitinated proteins (Kumagai et al., 2015) (Figure 2). Therefore, the role of Cox-2, which is upregulated by SP1, in the oxidative stress state of neurons and glial cells during the onset of ischemic stroke needs to be further explored.

\section{Damaging and Protective Effects of SP1 via HIF-1}

Hypoxia-inducible factor- $1 \alpha$ (HIF- $1 \alpha$ ), mostly expressed in microglias and neurons during the onset of ischemic stroke, is a transcription factor that regulates oxygen levels. Its promoter involves the SP1 binding sites, suggesting the potential role of SP1 to induce HIF-1 gene transcription under hypoxia
(Rhim et al., 2013). In astrocytes, matrix metalloproteinase2 (MMP-2), activated via a hypoxia-inducible factor-1 $\alpha$ (HIF$1 \alpha)$-dependent mechanism, affects the vascular nerve unit (VNU) and eventually degrades the tight junctions of the BBB and induces BBB breakdown (Abdullahi et al., 2018). In addition, HIF- $1 \alpha$ may promote an inflammatory response through the NLRP3 inflammasome after stroke (Jiang et al., 2020). Besides, SP1 can co-localize with HIF-1 and histone acetyltransferase p300 in the $\mathrm{Na}^{+} / \mathrm{Ca}^{2+}$ exchanger 1 (NCX1) gene sequence, causing epigenetic changes and upregulation of NCX1 expression, producing neuronal protective effects, which will be further discussed in the following Section 3.5 (Formisano et al., 2015).

\section{SP1 and Ion Transporters on the Cytosolic Membrane}

$\mathrm{Na}^{+} / \mathrm{Ca}^{2+}$ exchanger 1 has been proved to be crucial in attenuating brain injury after cerebral ischemia (Valsecchi et al., 2011; Chuang et al., 2017). NCX regulates both the intracellular and extracellular contents of $\mathrm{Na}^{+}$and $\mathrm{Ca}^{2+}$ according to membrane potential and transmembrane ion gradients (Shenoda, 2015). It was found that by transient middle cerebral artery occlusion (tMCAO) in rats, SP1 and HIF-1 colocalized with histone acetyltransferase p300 on NCX1-brain promoter in cortical neurons and SP1/HIF-1/p300 resulted in high acetylation of NCX1-brain histone H3. Moreover, SP1 is a transcriptional activator of NCX1. The overexpression of NCX1 can counteract the death-promoting effect of p300 inhibitors on neurons under OGD/R condition. It is evident that SP1 ultimately shows a neuronal protective effect through NCX1 overexpression and epigenetic alterations caused by $\mathrm{p} 300$ (Formisano et al., 2015). It is worth noting that the development of drugs that modulate NCX1 by promoting its upregulation in stroke or through epigenetic changes can provide a novel and promising pharmacological way to ameliorate neuronal injury during cerebral ischemia.

However, SP1 does not just simply exert a protective effect on neurons and glial cells under ischemia or OGD/R, as there has evidence that it can also exacerbate the damage caused by ischemia.

Sulfonylurea receptor 1 (SUR1) is a member of the ATPbinding cassette (ABC) transporter protein family, and SUR1$\mathrm{NC}_{\mathrm{Ca}}$-ATP channels, also called SUR1-TRPM4 heterodimer, are almost absent in normal brain. SUR1-TRPM4 channels are composed of the $\mathrm{Ca}^{2+}$-activated nonselective ion channel TRPM4 and the regulatory subunit SUR1 (Mehta et al., 2015). In the state of oxidative stress caused by ischemia, SP1 and HIF-1 bind to the promoter of the $A b c c 8$ gene encoding SUR1 (Simard et al., 2012; Woo et al., 2012). In astrocytes and microvascular endothelial cells, the upregulation of SUR1 regulates TRPM4 for nonselective monovalent cation endocytosis. The heterologous complex SUR1-TRPM4-AQP4, formed by combining with AQP4, can enhance the permeability to water and ions, thus leading to the edema of astrocytes and enlarged infarct size (Simard et al., 2012; Stokum et al., 2018). 


\section{Exacerbating Glutamate Excitotoxicity by Affecting t-PA}

Tissue-type plasminogen activator ( $\mathrm{t}-\mathrm{PA}$ ) is a fibrinogen activator that converts fibrinolytic enzymogen into fibrinolytic enzymes, triggering fibrinolysis and promoting clot lysis. By far, t-PA has been the only choice for thrombolytic therapy in acute ischemic stroke, but recent studies have shown that it has farreaching effects on many other systems beyond the hematologic system, such as the immune system, the nervous system, and so forth (Draxler et al., 2019). In the brain, t-PA is produced by neurons, microglia, endothelial cells, and astrocytes, whose low-level expression can be witnessed in synaptic remodeling processes under physiological conditions.

In neurons and glial cells, enhanced t-PA levels during cerebral ischemia can influence the size of the infarct from ischemic stroke. The $t-P A$ gene promoter can be regulated by many hormones, such as steroid hormones, to increase transcriptional activity under the induction of SP1. The ubiquitous character of polymorphisms of $t-P A$ gene sequences is associated with the release of t-PA. The abundance of the wild-type $\mathrm{C}$ allele is approximately $30 \%$ more than that of the mutant $\mathrm{T}$ allele, and the t-PA enhancer-7351C > T SNP diminishes the affinity of SP1 for this locus, a change that reduces the release of t-PA and thus affects the final infarct size in cerebral ischemia (Tjarnlund-Wolf et al., 2011). It is worth noting that high levels of t-PA during ischemia may increase the excitotoxicity of glutamate through the cleavage and activation of NMDA receptors, ultimately aggravating the death of neurons and glial cells (Lopez-Atalaya et al., 2008). In the acute phase of ischemic stroke, neuronal and astrocyte t-PA secretion levels become the determinants of infarct size and long-term recovery. However, in the recovery phase of ischemic stroke, exogenous t-PA may increase the axon regeneration of the cerebral cortex through the epidermal growth factor receptor (EGFR) signaling pathway (Pu et al., 2019).

\section{Exacerbating Adverse Cerebral Vasoconstriction via $\mathrm{ET}_{\mathrm{B}} \mathrm{R}$ Upregulation}

It has been found that certain contractile $G$ protein-coupled receptors are increased in brain tissue after ischemia-reperfusion (I/R) in human cerebral vessels (Edvinsson and Povlsen, 2011), among which the increases in endothelin type $A\left(E T_{A} R\right)$ and type $B$ receptors $\left(\mathrm{ET}_{\mathrm{B}} \mathrm{R}\right)$ are involved in the pathological process after stroke. Endothelin-1 (ET-1) plays a vasoconstrictive role in $\mathrm{I} / \mathrm{R}$, leading to a worsened prognosis. SP1, phosphorylated by ERK1/2, effectively upregulates $\mathrm{ET}_{\mathrm{B}} \mathrm{R}$ expression in human cerebral arterial smooth muscle (Grell et al., 2014).

\section{Role of SP1 in Cerebral Hemorrhage}

In the region of cortical contusion, SUR1 has also witnessed a significant upregulation in the cerebral cortex, microvasculature, and neurons. Thereafter, the formation of SUR1-TRPM4 channels can swell vascular endothelial cells, whose death could disrupt the vascular integrity and aggravate ischemia. By blocking the microvascular Abcc8 gene, secondary hemorrhage after brain contusion can be reduced (Simard et al., 2009). Similarly, hemorrhagic necrosis occurring from spinal cord injury is transiently suppressed by inhibiting SUR1 expression (Simard et al., 2010). SUR1 is also upregulated in microvascular endothelial cells when an ischemic stroke occurs. The specific results are not elaborated, but the outcome may be similar to that of SUR1 upregulation after brain contusion.

SP1 and transcription factor AP-2 (TFAP2C) could upregulate glutathione peroxidase 4 (GPX4) expression (Dai et al., 2020). Studies have shown that pharmacological selenium or Tat SelPep (a selenoprotein that transports selenium intracellularly) significantly enhances the binding of TFAP2C and SP1 to GPX4 gene upstream, increasing GPX4 expression and protecting neurons from hemin-induced iron death. It has also been demonstrated that inhibition of SP1 activity has almost completely abolished the role of Tat SelPep in the model of cerebral hemorrhage, indicating the central role of SP1 in the antioxidant processes in neuronal cells regulated by selenium (Alim et al., 2019). Selenium also seems to play an important neuroprotective role in ischemic stroke. By targeting selenium nanoparticles in the ischemic region of the central nervous system, it can modulate cellular metabolism, anti-oxidation, anti-inflammation, neuron repair, and many other signaling pathways, which play a crucial role in resisting ischemic stroke (Amani et al., 2019). Analogous to hemorrhagic stroke, the upregulation of SP1 may enhance the effect of selenium in ischemic stroke.

\section{THERAPEUTIC STRATEGIES BASED ON SP1 AND FUTURE PROSPECTS}

According to the summary about the role of SP1 in the development of ischemic stroke in this review, it is through the upregulation of SP1 level and the reduction of its degradation that the protective function of SP1 takes effect. As mentioned above, the promoter of the survivin gene has many SP1-binding sites, and it has been shown that Tanshinone IIA may exert neuroprotective effects after ischemia through the activation of the SP1/survivin pathway (Tang et al., 2019). In addition, SP1 promotes NCX1 overexpression and attenuates brain edema, and the development of drugs that modulate NCX1 by promoting its upregulation in stroke or through epigenetic changes may be a novel pharmacological pathway to improve neuronal injury during cerebral ischemia. Quite importantly, SP1 plays an antioxidant role during ischemic stroke. Through the activation of the endogenous SP1 gene or the reduction of SP1 degradation, it is possible to promote its role as an antioxidant and attenuate the damage caused by ischemia. Curcumin exerts its antioxidant effect during I/R injury by activating SP1-dependent Prdx6 expression (Jia et al., 2017). Many studies have suggested that, in the near future, various novel drugs and therapies can be developed to elevate the intracellular level of SP1. In the study of renal vascular I/R, investigators innovatively used humaninduced pluripotent stem cell-derived mesenchymal stromal cellextracellular vesicles (hiPSC-MSCs-EV) to target SP1 delivery to protect the kidney from I/R injury (Yuan et al., 2017). Apart from that, it has been experimentally demonstrated that the upregulation of SP1 is accompanied by the reduction of 


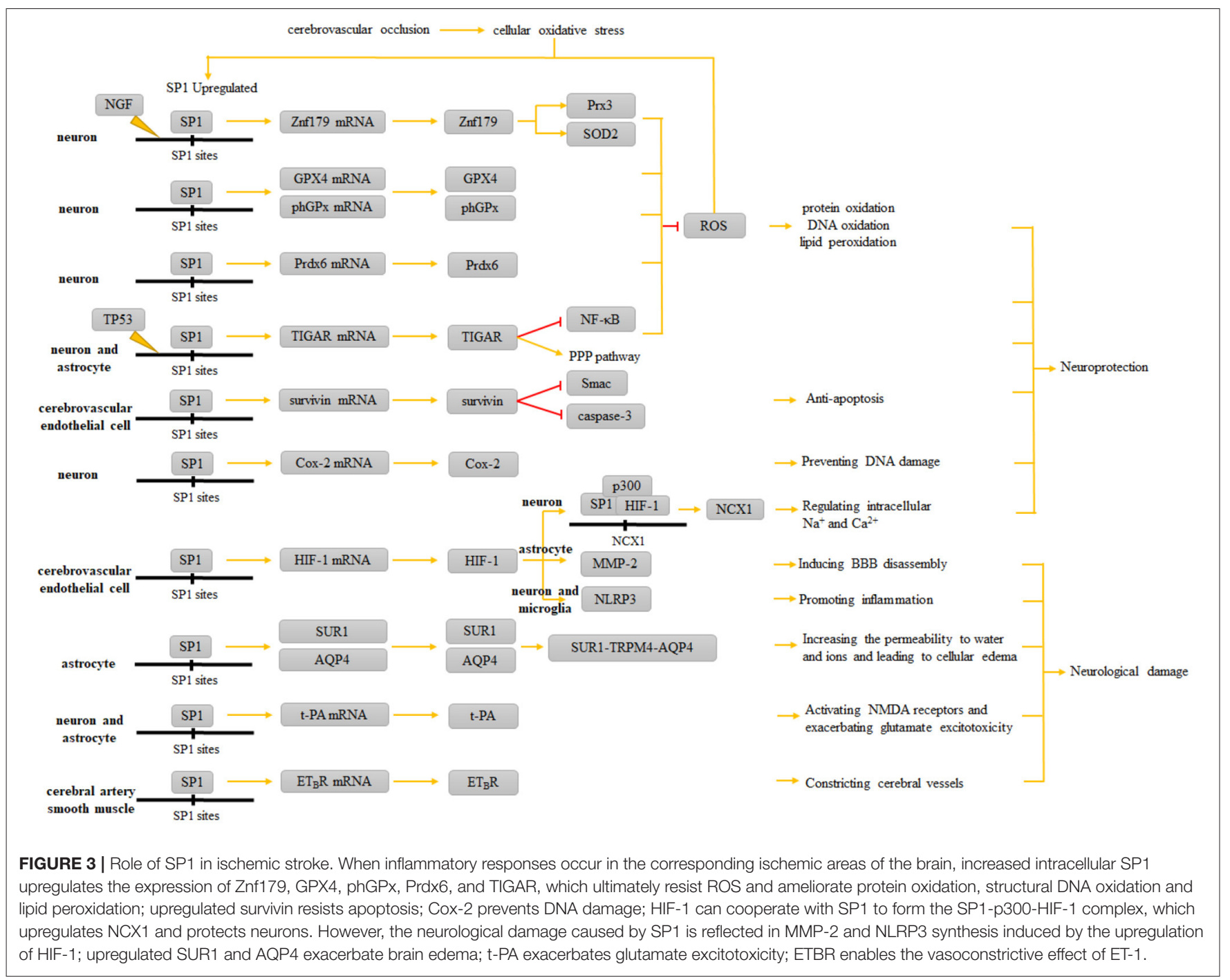

myocardial and intestinal I/R injury, embodying its protective role effectively (Li et al., 2019b; Hu et al., 2020).

Conversely, taking into account its deteriorating effects in ischemic stroke, it is necessary to reduce the SP1 level or disturb and attenuate its downstream results. SP1 promotes the formation of SUR1-NC $\mathrm{Ca}$-ATP channels, a complex that exacerbates brain edema. Glibenclamide targeting of SUR1 provides a therapeutic approach to prevent and treat brain swelling in ischemic stroke (Woo et al., 2020). Interfering with the binding activity of SP1 to the $A b c c 8$ gene promoter is one of the existing ways to improve cellular edema in a state of oxidative stress in the brain, and resveratrol has been shown to have this effect (Alquisiras-Burgos et al., 2020). Some strong antioxidants such as polyphenolic compounds like CUR, glutathione byproducts like NAC, affect the expression of SUR1 in oxidative stress by dampening the activity of $\mathrm{SP} 1$ and NF- $\mathrm{B} / \mathrm{p} 65$ transcription factors (Chatterjee et al., 2019). Given that SP1 elevates ETBR levels and exacerbates cerebral ischemia, relevant studies have confirmed that mithramycin A can be used to reduce ETBR expression on cerebral arterial smooth muscle after I/R (Grell et al., 2014).

Interestingly, the levels of certain miRNAs are altered during cerebral ischemia, and SP1 can serve as a target of these miRNAs related to stroke. Hence, further epigenetic researches hold a quite promising future for stroke treatment. When the proinflammatory role of SP1 in ischemic stroke is confirmed, various treatments aimed at its reduction can be learned from similar methods used in the cures of other diseases. With the evidence showing its association with tumorigenesis, SP1 also gets actively involved in several cancers (Beishline and AzizkhanClifford, 2015). In ovarian cancer studies, SP1 has been found to regulate genes overexpressed in the cancer process, and the direct targeting of it by miR-128 and miR-377 can retard the proliferation of cancer cells (Chen et al., 2019). Various treatments and drugs targeting SP1 have been investigated to cure 
TABLE 2 | Roles and significance of SP1 in ischemic stroke.

\begin{tabular}{|c|c|c|c|c|}
\hline & Function & Cell type & Physiological significance & Reference \\
\hline \multirow[t]{4}{*}{ Protective effects } & Antioxidant & Neuron and astrocyte & $\begin{array}{l}\text { SP1 binds to the promoters of } \\
\text { Znf179, GPX4, Prdx6, and TIGAR } \\
\text { genes to increase the expression of } \\
\text { the corresponding genes, ultimately } \\
\text { protecting neurons through } \\
\text { antioxidant effects. }\end{array}$ & $\begin{array}{l}\text { Zou et al., 2012; Su et al., } \\
\text { 2016; Zhou et al., 2016; } \\
\text { Chuang et al., 2017; Jia } \\
\text { et al., 2017; Chen et al., } \\
\text { 2018; Wu et al., } 2018\end{array}$ \\
\hline & Anti-apoptosis & $\begin{array}{l}\text { Cerebrovascular endothelial } \\
\text { cell }\end{array}$ & $\begin{array}{l}\text { SP1 activates survivin transcription } \\
\text { and exerts neuroprotective effects } \\
\text { through the SP1/survivin pathway. }\end{array}$ & Mallolas et al., 2014 \\
\hline & Preventing DNA damage & Neuron & $\begin{array}{l}\text { SP1 binds to the promoter of Cox-2 } \\
\text { and promotes Cox- } 2 \text { expression, } \\
\text { preventing DNA damage. }\end{array}$ & Lee et al., 2006 \\
\hline & $\begin{array}{l}\text { Promoting } \mathrm{Na}^{+} / \mathrm{Ca}^{2+} \\
\text { transporter } 1 \text { expression }\end{array}$ & Neuron & $\begin{array}{l}\text { SP1 and HIF-1 together with histone } \\
\text { acetyltransferase p300 are localized } \\
\text { to NCX1 promoter, and NCX1 } \\
\text { overexpression counteracts p300 } \\
\text { inhibition-induced neural death. }\end{array}$ & $\begin{array}{l}\text { Formisano et al., 2015; } \\
\text { Shenoda, } 2015\end{array}$ \\
\hline \multirow[t]{4}{*}{ Damaging effects } & $\begin{array}{l}\text { Inducing BBB catabolism } \\
\text { and inflammatory response }\end{array}$ & $\begin{array}{l}\text { Astrocyte (for BBB } \\
\text { catabolism) and neuron and } \\
\text { microglia (for inflammatory } \\
\text { response) }\end{array}$ & $\begin{array}{l}\text { SP1 induces HIF-1 gene transcription } \\
\text { under hypoxia. MMP-2 activated by } \\
\text { HIF-1 } 1 \alpha \text {-dependent mechanism can } \\
\text { induce BBB catabolism, while HIF-1 } \alpha \\
\text { regulates the inflammatory response } \\
\text { through the NLRP3 inflammasome } \\
\text { complex. }\end{array}$ & $\begin{array}{l}\text { Abdullahi et al., 2018; Jiang } \\
\text { et al., } 2020\end{array}$ \\
\hline & Leading to cerebral edema & Astrocyte & $\begin{array}{l}\text { SP1 promotes the formation of } \\
\text { SUR1-TRPM4-AQP4 complex that } \\
\text { increases permeability to water and } \\
\text { ions, leading to cellular edema. }\end{array}$ & $\begin{array}{l}\text { Simard et al., 2012; Woo } \\
\text { et al., 2012; Stokum et al., } \\
2018\end{array}$ \\
\hline & $\begin{array}{l}\text { Exacerbating glutamate } \\
\text { excitotoxicity }\end{array}$ & Neuron and astrocyte & $\begin{array}{l}\text { SP1 binds to the enhancer of t-PA, } \\
\text { promoting the release of t-PA which } \\
\text { activates NMDA receptors and } \\
\text { exacerbating glutamate excitotoxicity. }\end{array}$ & Lopez-Atalaya et al., 2008 \\
\hline & $\begin{array}{l}\text { Constricting cerebral } \\
\text { vessels }\end{array}$ & $\begin{array}{l}\text { Cerebral artery smooth } \\
\text { muscle }\end{array}$ & $\begin{array}{l}\text { SP1 upregulates } \mathrm{ET}_{\mathrm{B}} \mathrm{R} \text { expression, } \\
\text { which enables ET-1 to exert a } \\
\text { vasoconstrictive effect. }\end{array}$ & Grell et al., 2014 \\
\hline
\end{tabular}

cancers. For example, mithramycin A and its analogs can block the binding of SP1 to the gene and further inhibit its function as a transcription factor in multiple ways (Previdi et al., 2010; Sankpal et al., 2011).

In addition, many studies have proved the proinflammatory effects of SP1, which are quite common in neurodegenerative diseases. An increase in SP1 is also associated with inflammatory responses in degenerative diseases of the central nervous system. SP1, a proinflammatory factor, is significantly elevated in the brain in patients with Alzheimer's disease or Parkinson's disease. It has been found that upregulation of miR-375 attenuates dopaminergic neuronal damage in Parkinson's disease by inhibiting SP1 and attenuating oxidative stress and inflammatory responses (Cai et al., 2020). Moreover, during spinal cord I/R injury, miRNA-128-3p exerted a neuroprotective and inflammation-reducing effect by inhibiting SP1 and reducing the proinflammatory factors IL-6, TNF- $\alpha$, and IL-1 $\beta$ (Wang et al., 2020). The important role of SP1 in upregulating inflammatory factors indicated in the studies mentioned above also implies that through the inhibition of SP1, the reduction of inflammatory factors and cell protection can be achieved. Although many studies and reports on SP1 affecting inflammatory factors in neurodegenerative diseases are currently available, the relationship between SP1 and inflammatory factors in ischemic stroke still needs further investigation.

SP1 is a common DNA-binding protein involved in a variety of physiological and pathophysiological processes. In this review, we present a comprehensive overview on the roles of SP1 as both an antioxidant and anti-apoptotic agent, as well as how it affects the cytosolic ion transporters and promotes inflammation in ischemic stroke events. It is not difficult to find that SP1 has both protective and non-protective effects on neurons and neuroglial cells (Figure 3 and Table 2). Further studies on the role of SP1 in ischemic stroke should focus on clarifying the periods and stages when SP1 exerts different effects, the situations where its effects tend to be protective or damaging, and the factors that influence the manifestations of its diverse effects. In the future, the role of SP1 in ischemic stroke and related treatment needs detailed 
investigation to amplify its protective role while dampening its damaging effects.

\section{AUTHOR CONTRIBUTIONS}

MZ conceptualized the study, acquired funding, and administered the project. QY, MZ, and WL wrote the original draft. ZC provided the resources. MZ, QY, and ZC reviewed and edited the manuscript. All authors contributed to the article and approved the submitted version.

\section{REFERENCES}

Abdullahi, W., Tripathi, D., and Ronaldson, P. T. (2018). Blood-brain barrier dysfunction in ischemic stroke: targeting tight junctions and transporters for vascular protection. Am. J. Physiol. Cell. Physiol. 315, C343-c356. doi: 10.1152/ajpcell.00095.2018

Alim, I., Caulfield, J. T., Chen, Y., Swarup, V., Geschwind, D. H., Ivanova, E., et al. (2019). Selenium drives a transcriptional adaptive program to block ferroptosis and treat stroke. Cell. 177, 1262-1279.e1225. doi: 10.1016/j.cell.2019.03.032

Alquisiras-Burgos, I., Ortiz-Plata, A., Franco-Pérez, J., Millán, A., and Aguilera, P. (2020). Resveratrol reduces cerebral edema through inhibition of de novo SUR1 expression induced after focal ischemia. Exp. Neurol. 330, 113353. doi: 10.1016/j.expneurol.2020.113353

Amani, H., Habibey, R., Shokri, F., Hajmiresmail, S. J., Akhavan, O., Mashaghi, A., et al. (2019). Selenium nanoparticles for targeted stroke therapy through modulation of inflammatory and metabolic signaling. Sci. Rep. 9, 6044. doi: 10.1038/s41598-019-42633-9

An, Y., Belevych, N., Wang, Y., Zhang, H., Herschman, H., Chen, Q., et al. (2014). Neuronal and nonneuronal COX-2 expression confers neurotoxic and neuroprotective phenotypes in response to excitotoxin challenge. J. Neurosci. Res. 92, 486-495. doi: 10.1002/jnr.23317

Arhab, Y., Bulakhov, A. G., Pestova, T. V., and Hellen, C. U. T. (2020). Dissemination of internal ribosomal entry sites (IRES) between viruses by horizontal gene transfer. Viruses. 12, 612. doi: 10.3390/v12060612

Ayala, A., Muñoz, M. F., and Argüelles, S. (2014). Lipid peroxidation: production, metabolism, and signaling mechanisms of malondialdehyde and 4-hydroxy-2nonenal. Oxid Med Cell Longev 2014, 360438. doi: 10.1155/2014/360438

Beishline, K., and Azizkhan-Clifford, J. (2015). Sp1 and the 'hallmarks of cancer'. Febs. J. 282, 224-258. doi: 10.1111/febs.13148

Bornes, S., Prado-Lourenco, L., Bastide, A., Zanibellato, C., Iacovoni, J. S., Lacazette, E., et al. (2007). Translational induction of VEGF internal ribosome entry site elements during the early response to ischemic stress. Circ. Res. 100, 305-308. doi: 10.1161/01.RES.0000258873.08041.c9

Cai, L. J., Tu, L., Li, T., Yang, X. L., Ren, Y. P., Gu, R., et al. (2020). Up-regulation of microRNA-375 ameliorates the damage of dopaminergic neurons, reduces oxidative stress and inflammation in Parkinson's disease by inhibiting SP1. Aging (Albany NY). 12, 672-689. doi: 10.18632/aging. 102649

Campbell, B. C. V., De Silva, D. A., Macleod, M. R., Coutts, S. B., Schwamm, L. H., Davis, S. M., et al. (2019). Ischaemic stroke. Nat. Rev. Dis. Primers. 5, 70. doi: 10.1038/s41572-019-0118-8

Chatterjee, B., Ghosh, K., Suresh, L., and Kanade, S. R. (2019). Curcumin ameliorates PRMT5-MEP50 arginine methyltransferase expression by decreasing the Sp1 and NF-YA transcription factors in the A549 and MCF-7 cells. Mol. Cell Biochem. 455, 73-90. doi: 10.1007/s11010-018-3471-0

Chen, J., Zhang, D. M., Feng, X., Wang, J., Qin, Y. Y., Zhang, T., et al. (2018). TIGAR inhibits ischemia/reperfusion-induced inflammatory response of astrocytes. Neuropharmacology. 131, 377-388. doi: 10.1016/j.neuropharm.2018.01.012

Chen, Y. T., Tsai, H. P., Wu, C. C., Chen, C. Y., Chai, C. Y., and Kwan, A. L. (2019). High-level Sp1 is Associated with Proliferation, Invasion, and Poor Prognosis in Astrocytoma. Pathol. Oncol. Res. 25, 1003-1013. doi: $10.1007 / \mathrm{s} 12253-018-0422-8$

\section{FUNDING}

This research was funded by the Natural Science Foundations for Excellent Young Scholars of Hunan Province (No. 2021JJ20095), the Key Research and Development Program of Hunan Province (No. 2020SK2063), Research Project on Education and Teaching Innovation of Central South University (2021jy145), the Natural Science Foundations of Hunan Province (No. 2020JJ4134), and the National Natural Science Foundation of China (No. 81501025).

Chuang, J. Y., Kao, T. J., Lin, S. H., Wu, A. C., Lee, P. T., Su, T. P., et al. (2017). Specificity protein 1-zinc finger protein 179 pathway is involved in the attenuation of oxidative stress following brain injury. Redox. Biol. 11, 135-143. doi: 10.1016/j.redox.2016.11.012

Dai, C., Chen, X., Li, J., Comish, P., Kang, R., and Tang, D. (2020). Transcription factors in ferroptotic cell death. Cancer Gene. Ther. 27, 645-656. doi: 10.1038/s41417-020-0170-2

Draxler, D. F., Lee, F., Ho, H., Keragala, C. B., Medcalf, R. L., and Niego, B. (2019). t-PA Suppresses the Immune Response and Aggravates Neurological Deficit in a Murine Model of Ischemic Stroke. Front. Immunol. 10, 591. doi: 10.3389/fimmu.2019.00591

Duan, L., Perez, R. E., Chen, L., Blatter, L. A., and Maki, C. G. (2018). p53 promotes AKT and SP1-dependent metabolism through the pentose phosphate pathway that inhibits apoptosis in response to Nutlin-3a. J. Mol. Cell Biol. 10, 331-340. doi: $10.1093 / j m c b / m j x 051$

Edvinsson, L. I., and Povlsen, G. K. (2011). Vascular plasticity in cerebrovascular disorders. J. Cereb. Blood Flow. Metab. 31, 1554-1571. doi: $10.1038 /$ jcbfm. 2011.70

Fisher, A. B. (2011). Peroxiredoxin 6: a bifunctional enzyme with glutathione peroxidase and phospholipase $\mathrm{A}_{2}$ activities. Antioxid. Redox. Signal. 15, 831-844. doi: 10.1089/ars.2010.3412

Fletcher, S. C., Grou, C. P., Legrand, A. J., Chen, X., Soderstrom, K., Poletto, M., et al. (2018). Sp1 phosphorylation by ATM downregulates BER and promotes cell elimination in response to persistent DNA damage. Nucleic. Acids Res. 46, 1834-1846. doi: 10.1093/nar/gkx1291

Formisano, L., Guida, N., Valsecchi, V., Cantile, M., Cuomo, O., Vinciguerra, A., et al. (2015). Sp3/REST/HDAC1/HDAC2 complex represses and Sp1/HIF$1 /$ p300 complex activates ncxl gene transcription, in brain ischemia and in ischemic brain preconditioning, by epigenetic mechanism. J. Neurosci. 35, 7332-7348. doi: 10.1523/JNEUROSCI.2174-14.2015

Gilmour, J., O'Connor, L., Middleton, C. P., Keane, P., Gillemans, N., Cazier, J. B., et al. (2019). Robust hematopoietic specification requires the ubiquitous Sp1 and Sp3 transcription factors. Epigenetics Chromatin. 12, 33. doi: 10.1186/s13072-019-0282-9

Godet, A. C., David, F., Hantelys, F., Tatin, F., Lacazette, E., Garmy-Susini, B., et al. (2019). IRES trans-acting factors, key actors of the stress response. Int. J. Mol. Sci. 20, 924. doi: 10.3390/ijms20040924

González-Nieto, D., Fernández-Serra, R., Pérez-Rigueiro, J., Panetsos, F., Martinez-Murillo, R., and Guinea, G. V. (2020). Biomaterials to neuroprotect the stroke brain: a large opportunity for narrow time windows. Cells. 9, 1074. doi: $10.3390 /$ cells 9051074

Grell, A. S., Thigarajah, R., Edvinsson, L., and Samraj, A. K. (2014). Regulatory mechanism of endothelin receptor B in the cerebral arteries after focal cerebral ischemia. PLoS ONE. 9, e113624. doi: 10.1371/journal.pone.0113624

Hu, Y., Zhang, C., Zhu, H., Wang, S., Zhou, Y., Zhao, J., et al. (2020). Luteolin modulates SERCA2a via $\mathrm{Sp} 1$ upregulation to attenuate myocardial ischemia/reperfusion injury in mice. Sci. Rep. 10, 15407. doi: 10.1038/s41598-020-72325-8

Jia, G., Tan, B., Ma, J., Zhang, L., Jin, X., and Li, C. (2017). Prdx6 upregulation by curcumin attenuates ischemic oxidative damage via SP1 in rats after stroke. Biomed. Res. Int. 2017, 6597401. doi: 10.1155/2017/6597401

Jiang, Q., Geng, X., Warren, J., Eugene Paul Cosky, E., Kaura, S., Stone, C., et al. (2020). hypoxia inducible factor-1 $\alpha$ (HIF-1 $\alpha)$ mediates NLRP3 
inflammasome-dependent-pyroptotic and apoptotic cell death following ischemic stroke. Neuroscience. 448, 126-139. doi: 10.1016/j.neuroscience.2020. 09.036

Kovacevic Grujicic, N., Mojsin, M., Krstic, A., and Stevanovic, M. (2005). Functional characterization of the human SOX3 promoter: identification of transcription factors implicated in basal promoter activity. Gene. 344, 287-297. doi: 10.1016/j.gene.2004.11.006

Kumagai, T., Usami, H., Matsukawa, N., Nakashima, F., Chikazawa, M., Shibata, T., et al. (2015). Functional interaction between cyclooxygenase-2 and $\mathrm{p} 53$ in response to an endogenous electrophile. Redox. Biol. 4, 74-86. doi: 10.1016/j.redox.2014.11.011

Lee, J., Kosaras, B., Aleyasin, H., Han, J. A., Park, D. S., Ratan, R. R., et al. (2006). Role of cyclooxygenase-2 induction by transcription factor Sp1 and Sp3 in neuronal oxidative and DNA damage response. Faseb. J. 20, 2375-2377. doi: 10.1096/fj.06-5957fje

Lee, P., Hock, A. K., Vousden, K. H., and Cheung, E. C. (2015). p53- and p73independent activation of TIGAR expression in vivo. Cell Death Dis. 6, e1842. doi: 10.1038/cddis.2015.205

Lee, Y. C., Huang, W. C., Lin, J. H., Kao, T. J., Lin, H. C., Lee, K. H., et al. (2018). Znf179 E3 ligase-mediated TDP-43 polyubiquitination is involved in TDP43- ubiquitinated inclusions (UBI) (+)-related neurodegenerative pathology. J. Biomed. Sci. 25, 76. doi: 10.1186/s12929-018-0479-4

Li, L. T., Wang, X., Zhu, W. T., Qian, G. W., Pei, D. S., and Zheng, J. N. (2019a). Reciprocal role Of DNA methylation and Sp1 binding In Ki-67 gene transcription. Cancer Manag. Res. 11, 9749-9759. doi: 10.2147/CMAR.S213769

Li, Y., Feng, D., Wang, Z., Zhao, Y., Sun, R., Tian, D., et al. (2019b). Ischemia-induced ACSL4 activation contributes to ferroptosis-mediated tissue injury in intestinal ischemia/reperfusion. Cell Death Differ. 26, 2284-2299. doi: 10.1038/s41418-019-0299-4

Lim, K., Yoon, B. H., and Ha, C. H. (2015). O-Linked N-acetylglucosaminylation of Sp1 interferes with Sp1 activation of glycolytic genes. Biochem. Biophys. Res. Commun. 468, 349-353. doi: 10.1016/j.bbrc.2015.10.096

Lopez-Atalaya, J. P., Roussel, B. D., Levrat, D., Parcq, J., Nicole, O., Hommet, Y., et al. (2008). Toward safer thrombolytic agents in stroke: molecular requirements for NMDA receptor-mediated neurotoxicity. J. Cereb. Blood Flow. Metab. 28, 1212-1221. doi: 10.1038/jcbfm.2008.14

Mak, C. S., Yung, M. M., Hui, L. M., Leung, L. L., Liang, R., Chen, K., et al. (2017). MicroRNA-141 enhances anoikis resistance in metastatic progression of ovarian cancer through targeting KLF12/Sp1/survivin axis. Mol. Cancer. 16, 11. doi: 10.1186/s12943-017-0582-2

Mallolas, J., Rodríguez, R., Gubern, C., Camós, S., Serena, J., and Castellanos, M. (2014). A polymorphism in the promoter region of the survivin gene is related to hemorrhagic transformation in patients with acute ischemic stroke. Neuromolecular Med. 16, 856-861. doi: 10.1007/s12017-014-8333-7

Mansour, A., Nabil, M., Ali-Labib, R., Said, H., and Annos, F. (2012). Reciprocal expression of survivin and SMAC/DIABLO in primary breast cancer. Med Oncol 29, 2535-2542. doi: 10.1007/s12032-011-0129-0

Mehta, R. I., Tosun, C., Ivanova, S., Tsymbalyuk, N., Famakin, B. M., Kwon, M. S., et al. (2015). Sur1-trpm 4 cation channel expression in human cerebral infarcts. J. Neuropathol. Exp. Neurol. 74, 835-849. doi: 10.1097/NEN.0000000000000223

Previdi, S., Malek, A., Albertini, V., Riva, C., Capella, C., Broggini, M., et al. (2010). Inhibition of Sp1-dependent transcription and antitumor activity of the new aureolic acid analogues mithramycin SDK and SK in human ovarian cancer xenografts. Gynecol. Oncol. 118, 182-188. doi: 10.1016/j.ygyno.2010.03.020

Pu, H., Shi, Y., Zhang, L., Lu, Z., Ye, Q., Leak, R. K., et al. (2019). Proteaseindependent action of tissue plasminogen activator in brain plasticity and neurological recovery after ischemic stroke. Proc. Natl. Acad. Sci. U S A. 116, 9115-9124. doi: 10.1073/pnas.1821979116

Rakers, C., Schleif, M., Blank, N., Matuškov,á, H., Ulas, T., Händler, K., et al. (2019). Stroke target identification guided by astrocyte transcriptome analysis. Glia. 67, 619-633. doi: 10.1002/glia.23544

Rhim, T., Lee, D. Y., and Lee, M. (2013). Hypoxia as a target for tissue specific gene therapy. J. Control Release. 172, 484-494. doi: 10.1016/j.jconrel.2013. 05.021

Sankpal, U. T., Goodison, S., Abdelrahim, M., and Basha, R. (2011). Targeting Sp1 transcription factors in prostate cancer therapy. Med Chem 7, 518-525. doi: $10.2174 / 157340611796799203$
Shenoda, B. (2015). The role of $\mathrm{Na}+/ \mathrm{Ca} 2+$ exchanger subtypes in neuronal ischemic injury. Transl. Stroke. Res. 6, 181-190. doi: 10.1007/s12975-015-0395-9

Simard, J. M., Kilbourne, M., Tsymbalyuk, O., Tosun, C., Caridi, J., Ivanova, S., et al. (2009). Key role of sulfonylurea receptor 1 in progressive secondary hemorrhage after brain contusion. J. Neurotrauma 26, 2257-2267. doi: 10.1089/neu.2009.1021

Simard, J. M., Woo, S. K., Norenberg, M. D., Tosun, C., Chen, Z., Ivanova, S., et al. (2010). Brief suppression of Abcc8 prevents autodestruction of spinal cord after trauma. Sci. Transl. Med. 2, 28ra29. doi: 10.1126/scitranslmed.3000522

Simard, J. M., Woo, S. K., Schwartzbauer, G. T., and Gerzanich, V. (2012). Sulfonylurea receptor 1 in central nervous system injury: a focused review. J. Cereb. Blood Flow Metab. 32, 1699-1717. doi: 10.1038/jcbfm.2012.91

Song, Q., Feng, Y. B., Wang, L., Shen, J., Li, Y., Fan, C., et al. (2019). COX-2 inhibition rescues depression-like behaviors via suppressing glial activation, oxidative stress and neuronal apoptosis in rats. Neuropharmacology. 160, 107779. doi: 10.1016/j.neuropharm.2019.107779

Sonowal, H., and Ramana, K. V. (2019). 4-Hydroxy-Trans-2-Nonenal in the Regulation of Anti-Oxidative and Pro-Inflammatory Signaling Pathways. Oxid. Med. Cell Longev. 2019, 5937326. doi: 10.1155/2019/5937326

Stokum, J. A., Kwon, M. S., Woo, S. K., Tsymbalyuk, O., Vennekens, R., Gerzanich, V., et al. (2018). SUR1-TRPM4 and AQP4 form a heteromultimeric complex that amplifies ion/water osmotic coupling and drives astrocyte swelling. Glia. 66, 108-125. doi: 10.1002/glia.23231

Su, T. C., Lin, S. H., Lee, P. T., Yeh, S. H., Hsieh, T. H., Chou, S. Y., et al. (2016). The sigma-1 receptor-zinc finger protein 179 pathway protects against hydrogen peroxide-induced cell injury. Neuropharmacology. 105, 1-9. doi: 10.1016/j.neuropharm.2016.01.015

Sun, M., Li, M., Huang, Q., Han, F., Gu, J. H., Xie, J., et al. (2015). Ischemia/reperfusion-induced upregulation of TIGAR in brain is mediated by SP1 and modulated by ROS and hormones involved in glucose metabolism. Neurochem. Int. 80, 99-109. doi: 10.1016/j.neuint.2014. 09.006

Tan, N. Y., and Khachigian, L. M. (2009). Sp1 phosphorylation and its regulation of gene transcription. Mol. Cell. Biol. 29, 2483-2488. doi: 10.1128/MCB. 01828-08

Tang, N., Chang, J., Zeng, Y., and Zheng, J. (2019). Tanshinone IIA protects hypoxia-induced injury by preventing microRNA-28 up-regulation in PC-12 cells. Eur. J. Pharmacol. 854, 265-271. doi: 10.1016/j.ejphar.2019.04.030

Tjarnlund-Wolf, A., Hultman, K., Curtis, M. A., Faull, R. L., Medcalf, R. L., and Jern, C. (2011). Allelic imbalance of tissue-type plasminogen activator (tPA) gene expression in human brain tissue. Thromb. Haemost. 105, 945-953. doi: 10.1160/TH10-10-0682

Valsecchi, V., Pignataro, G., Del Prete, A., Sirabella, R., Matrone, C., Boscia, F., et al. (2011). NCX1 is a novel target gene for hypoxiainducible factor-1 in ischemic brain preconditioning. Stroke. 42, 754-763. doi: 10.1161/STROKEAHA.110.597583

Wang, D., Chen, F., Fang, B., Zhang, Z., Dong, Y., Tong, X., et al. (2020). MiR-128-3p Alleviates Spinal Cord Ischemia/Reperfusion Injury Associated Neuroinflammation and Cellular Apoptosis via SP1 Suppression in Rat. Front. Neurosci. 14, 609613. doi: 10.3389/fnins.2020.609613

Wang, S. C., Wang, S. T., Liu, H. T., Wang, X. Y., Wu, S. C., Chen, L. C., et al. (2017). Trichostatin A induces bladder cancer cell death via intrinsic apoptosis at the early phase and Sp1-survivin downregulation at the late phase of treatment. Oncol. Rep. 38, 1587-1596. doi: 10.3892/or.2017.5795

Wei, Z., Qi, X., Chen, Y., Xia, X., Zheng, B., Sun, X., et al. (2020). Bioinformatics method combined with logistic regression analysis reveal potentially important miRNAs in ischemic stroke. Biosci. Rep. 40, BSR20201154. doi: 10.1042/BSR20201154

Wheatley, S. P., and Altieri, D. C. (2019). Survivin at a glance. J. Cell Sci. 132, jcs223826. doi: 10.1242 /jcs.223826

Woo, S. K., Kwon, M. S., Geng, Z., Chen, Z., Ivanov, A., Bhatta, S., et al. (2012). Sequential activation of hypoxia-inducible factor 1 and specificity protein 1 is required for hypoxia-induced transcriptional stimulation of Abcc8. J. Cereb. Blood Flow. Metab. 32, 525-536. doi: 10.1038/jcbfm.2011.159

Woo, S. K., Tsymbalyuk, N., Tsymbalyuk, O., Ivanova, S., Gerzanich, V., and Simard, J. M. (2020). SUR1-TRPM4 channels, not K(ATP), mediate 
brain swelling following cerebral ischemia. Neurosci. Lett. 718, 134729. doi: 10.1016/j.neulet.2019.134729

Wu, C. C., Lee, P. T., Kao, T. J., Chou, S. Y., Su, R. Y., Lee, Y. C., et al. (2018). Upregulation of Znf179 acetylation by SAHA protects cells against oxidative stress. Redox. Biol. 19, 74-80. doi: 10.1016/j.redox.2018.08.001

Yang, W. B., Hsu, C. C., Hsu, T. I., Liou, J. P., Chang, K. Y., Chen, P. Y., et al. (2020). Increased activation of HDAC1/2/6 and Sp1 underlies therapeutic resistance and tumor growth in glioblastoma. Neuro. Oncol. 22, 1439-1451. doi: 10.1093/neuonc/noaal03

Yeh, S. H., Yang, W. B., Gean, P. W., Hsu, C. Y., Tseng, J. T., Su, T. P., et al. (2011). Translational and transcriptional control of $\mathrm{Spl}$ against ischaemia through a hydrogen peroxide-activated internal ribosomal entry site pathway. Nucleic Acids. Res. 39, 5412-5423. doi: 10.1093/nar/gkr161

Yuan, X., Li, D., Chen, X., Han, C., Xu, L., Huang, T., et al. (2017). Extracellular vesicles from human-induced pluripotent stem cell-derived mesenchymal stromal cells (hiPSC-MSCs) protect against renal ischemia/reperfusion injury via delivering specificity protein (SP1) and transcriptional activating of sphingosine kinase 1 and inhibiting necroptosis. Cell Death Dis. 8, 3200. doi: 10.1038/s41419-017-0041-4

Zhang, Y., Qu, Y., Niu, T., Wang, H., and Liu, K. (2017). O-GlcNAc modification of Sp1 mediates hyperglycaemia-induced ICAM-1 up-regulation in endothelial cells. Biochem Biophys Res Commun 484, 79-84. doi: 10.1016/j.bbrc.2017.01.068

Zheng, Q., Wang, C., Wang, L., Zhang, D., Liu, N., Ming, X., et al. (2018). Interaction with SP1, but not binding to the E-box motifs, is responsible for BHLHE40/DEC1-induced transcriptional suppression of CLDN1 and cell invasion in MCF-7 cells. Mol. Carcinog. 57, 1116-1129. doi: 10.1002/mc.22829
Zhou, J. H., Zhang, T. T., Song, D. D., Xia, Y. F., Qin, Z. H., and Sheng, R. (2016). TIGAR contributes to ischemic tolerance induced by cerebral preconditioning through scavenging of reactive oxygen species and inhibition of apoptosis. Sci. Rep. 6, 27096. doi: 10.1038/srep27096

Zou, S., Gu, Z., Ni, P., Liu, X., Wang, J., and Fan, Q. (2012). SP1 plays a pivotal role for basal activity of TIGAR promoter in liver cancer cell lines. Mol. Cell Biochem. 359, 17-23. doi: 10.1007/s11010-0110993-0

Conflict of Interest: The authors declare that the research was conducted in the absence of any commercial or financial relationships that could be construed as a potential conflict of interest.

Publisher's Note: All claims expressed in this article are solely those of the authors and do not necessarily represent those of their affiliated organizations, or those of the publisher, the editors and the reviewers. Any product that may be evaluated in this article, or claim that may be made by its manufacturer, is not guaranteed or endorsed by the publisher.

Copyright $\odot 2021 \mathrm{Yu}$, Liu, Chen and Zhang. This is an open-access article distributed under the terms of the Creative Commons Attribution License (CC BY). The use, distribution or reproduction in other forums is permitted, provided the original author(s) and the copyright owner(s) are credited and that the original publication in this journal is cited, in accordance with accepted academic practice. No use, distribution or reproduction is permitted which does not comply with these terms. 